\title{
Successful Deep Anterior Lamellar Keratoplasty in Pre-existing Descemet Membrane Perforation - A Case Series
}

\author{
Shreesha Kumar Kodavoor ${ }^{1}$, Bijita Deb ${ }^{1}$, Soundarya Balajee ${ }^{1}$, Ramamurthy Dandapani ${ }^{2}$ \\ ${ }^{1}$ Cornea Cataract and Refractive Services, The Eye Foundation, Coimbatore, India \\ ${ }^{2}$ Cataract and Refractive Services, The Eye Foundation, Coimbatore, India
}

Email address:

eskay_03@rediffmail.com(S. K. Kodavoor),drbijitadeb@gmail.com(B. Deb), soundslikeme@gmail.com (S. Balajee), drramamurthy@theeyefoundation.com (R. Dandapani)

${ }^{*}$ Corresponding author

\section{To cite this article:}

Shreesha Kumar Kodavoor, Bijita Deb, Soundarya Balajee, Ramamurthy Dandapani. Successful Deep Anterior Lamellar Keratoplasty in Pre-existing Descemet Membrane Perforation - A Case Series. International Journal of Ophthalmology \& Visual Science.

Vol. 5, No. 3, 2020, pp. 70-74. doi: 10.11648/j.ijovs.20200503.11

Received: June 16, 2020; Accepted: June 30, 2020; Published: July 13, 2020

\begin{abstract}
Aim: To analyse the outcome of Deep anterior lamellar keratoplasty (DALK) in cases of pre-existing DM (Descemet membrane) tear. Method: 14 eyes with pre-existing perforation (4 eyes with advanced keratoconus post collagen crosslinking and post Toric implantable collamer lens explantation and 10 eyes with post healed hydrops) who underwent DALK were included. Manual layer by layer dissection by a special technique was employed. Results: Minimum follow up-1 year. All patients had good post-operative results with mean UCVA preoperative and postoperative value of $1.35 \pm 0.25$ LogMAR and $0.68 \pm 0.19$ LogMAR respectively with ' $p$ ' value of 0.00001 which was significant. Mean astigmatism preoperative and postoperative was found to be $4.82 \pm 1.76 \mathrm{D}$ and $2.66 \pm 0.7 \mathrm{D}$ and ' $\mathrm{p}$ ' value was significant ( $\mathrm{p}=0.00042$ ). Mean endothelial count preoperative and postoperative was $2479.18 \pm 239.42 \mathrm{cells} / \mathrm{cm}^{2}$ and $2238.45 \pm 218.49 \mathrm{cell} / \mathrm{cm}^{2}$ with percentage reduction of $9.6 \%$ at 1 year. Two eyes among them had postoperative double anterior chamber and two eyes had wrinkling of $\mathrm{DM}$ due to the advanced nature of KC. Conclusion: DALK can be successful in patients with pre-existing DM perforation if careful precautions are taken. Also layer by layer technique with a centripetal dissection is preferred in such cases to prevent intraoperative scar extension.
\end{abstract}

Keywords: Pre-existing Descemet's Membrane Perforation, Post Hydrops DALK, DALK in DM Perforation

\section{Introduction}

Patients with keratoconus can present with acute painful condition known as acute hydrops due to rupture of DM (Descemet membrane) and aqueous entry into corneal stroma and reduction in visual acuity. Incidence range from 2.6 to 2.8\%.[1] Post hydrops, the inflammation, edema and pain subsides but all patients end up with irregular astigmatism which requires surgical correction. The surgery of choice in these cases is often debatable and for many decades been a full thickness keratoplasty (PK-penetrating keratoplasty). But after the popularization of DALK (Deep Anterior Lamellar Keratoplasty), many surgeons prefer it over PK in selected cases for its advantages.[2-4] However, performing DALK in a previously perforated $\mathrm{DM}$ is quite challenging and the authors here have described a technique for successful DALK in pre-existing DM perforation post hydrops and also in cases where DM has been perforated for any ocular surgeries (phakic intraocular lens) with poor outcome.

\section{Methods}

\subsection{Patients}

We report a case series of 14 eyes of 12 patients with preexisting DM perforation due to various causes (Table 1). Among them 10 eyes had healed hydrops. 4 eyes had advanced $\mathrm{KC}$, initially managed with collagen cross linking 
(C3R) followed by intraocular toric ICL (intraocular collamer lens) but with subsequent progression of the disease or patients unhappy with the outcome, with DALK being planned following ICL explanation. One among these patient's had Down's syndrome and three patients had VKC (vernal keratoconjunctivitis) as a coexisting condition.

Table 1. Details of all 14 eyes with pre-existing DM perforation and scar who underwent DALK.

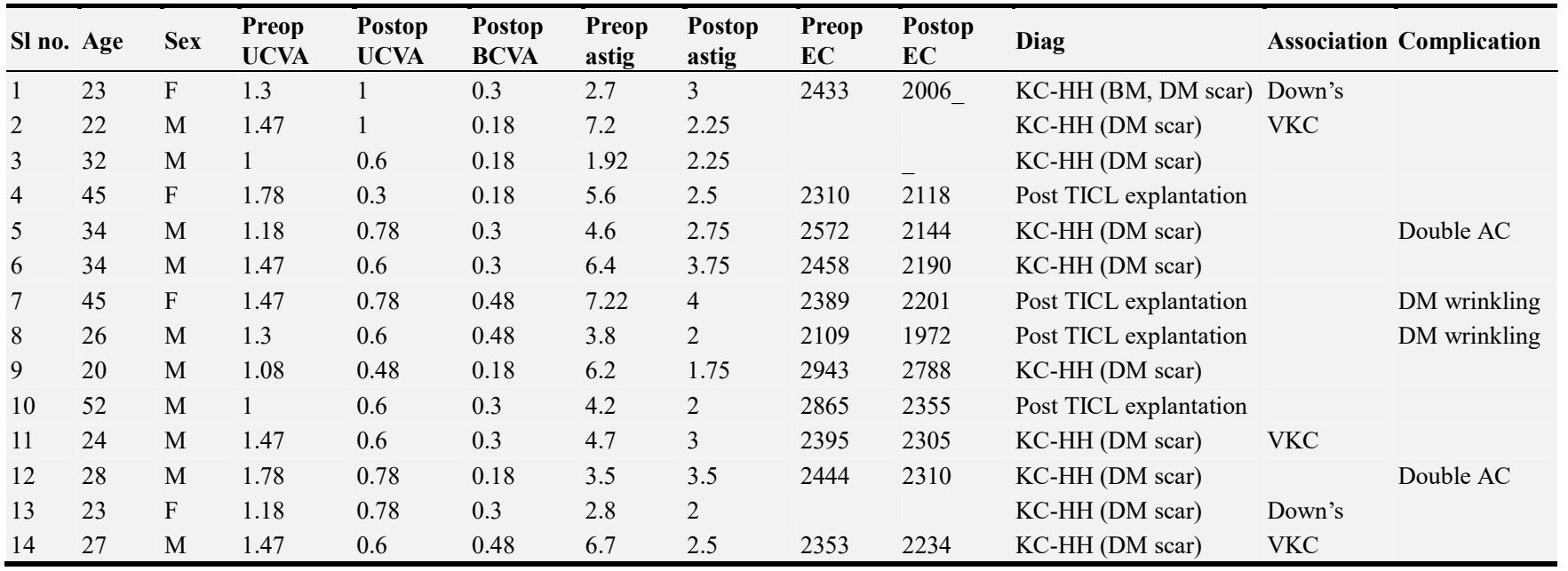

KC- Keratoconus, HH- Healed hydrops, BM Scar-Bowman membrane scar, DM Scar- Descemets membrane scar, T ICL-Toric implantable contact lens, UCVA-Uncorrected Visual acuity, BCVA- Best Corrected Visual Acuity, EC-Endothelial Count.

The case series is reported from a tertiary eye care centre done by a single experienced surgeon after obtaining an informed written consent and adhered to the tenets of the Declaration of Helsinki. Preoperative and postoperative slit lamp examination, visual acuity (UCVA-uncorrected visual acuity, BCVA- best corrected visual acuity), refraction, dilated fundus examination, topography (OCULUS Pentacam HR) and endothelial count (TOMEY; EM-3000) and Anterior segment optical coherence tomography were done wherever possible (Figure 1).
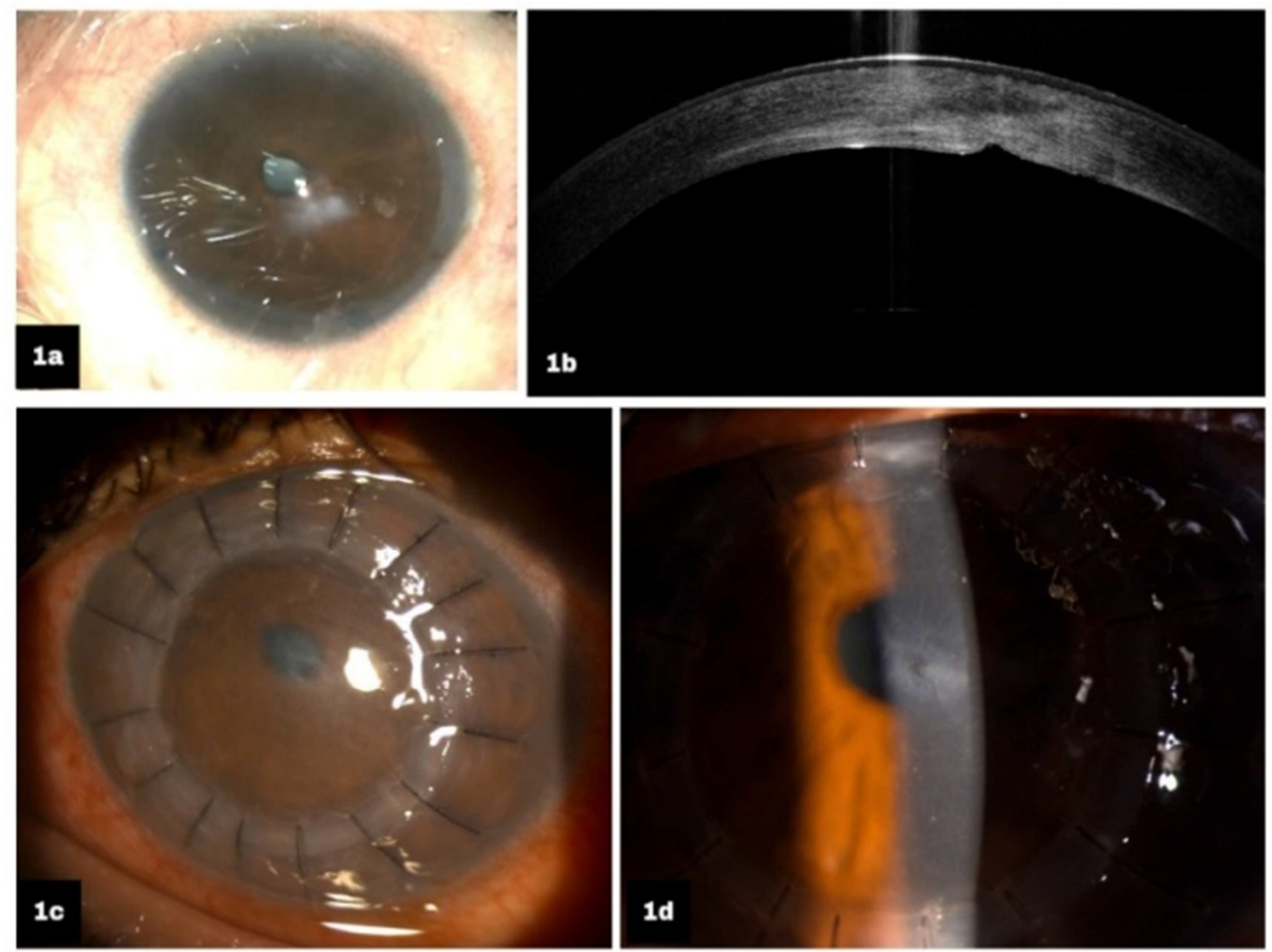

Figure 1. Pre operative and post operative images a) Slit lamp image showing healed paracentral scar; b) AS-OCT image showing healed DM tear; c) Post operative Day 1; d) Post operative 6 weeks.

\subsection{Technique}

All patients were operated under local anaesthesia (peribulbar block) with $2 \%$ lignocaine and were given preoperative intravenous mannitol $(20 \%, 2 \mathrm{~g} / \mathrm{kg}$ body weight over $30 \mathrm{~min}$ ) to lower the intraocular pressure during surgery 
and topical pilocarpine (2\%) to reduce chances of iatrogenic lens injury in case there was a need for conversion to PK. Trephine size of $8-8.5 \mathrm{~mm}$ for host cornea (involving the scar and cone area) was used with a $0.25 \mathrm{~mm}$ larger trephine size for donor cornea.

After partial trephination with a hand held steel trephine, crescent blade was used to create a small partial corneal lamellar pocket and manual layer by layer dissection technique was followed using a crescent blade and Lim's forceps for all cases to prevent sudden expansion of DM tear. Special care was taken to dissect the layers first from periphery and then towards the DM scar. This helped in preventing any inadvertent DM perforation at the beginning of surgery and thus a good lamellar dissection. As has been previously noted, healed hydrops with paracentral scarring had scarred margins compared to fresh intraoperative DM perforation due to any other cause. This also helped prevent any new DM perforation or enlargement of the same in post hydrops cases. In post TICL implantation or explantation cases the DM tear was located in the periphery (both main wound and paracentesis wound) and the dissection avoided the torn DM. In cases where anterior chamber collapse
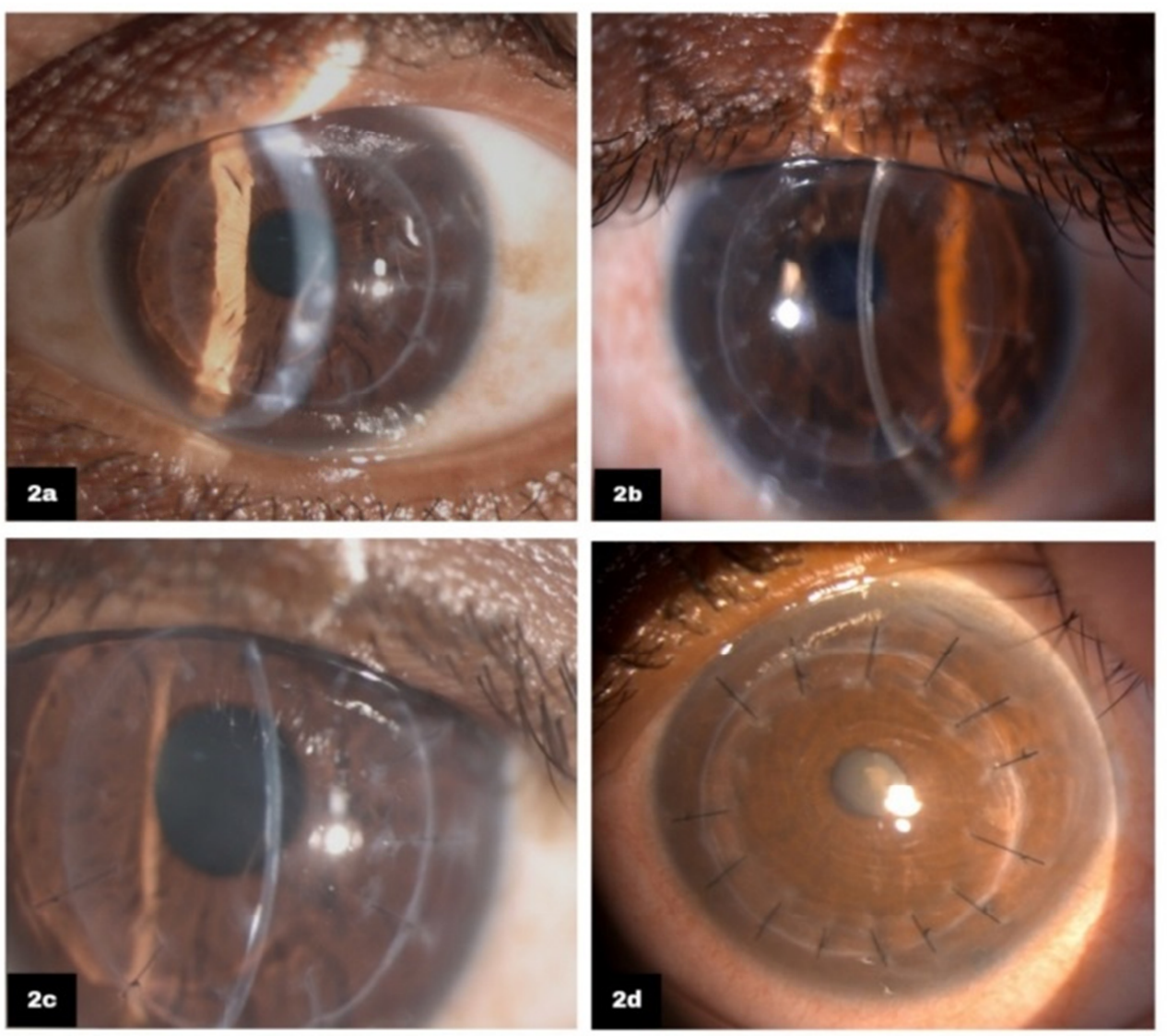

Figure 2. One year follow up images of various patients (a-c); d) Slit lamp image showing DM wrinkling.

\section{Results}

14 eyes of 12 patients were involved in the study carried out in a tertiary care centre which included four females and ten males of age group 20 to 52 years (mean occurred during dissection, air bubble was injected through the side port and anterior chamber was maintained and the DALK completed.

Graft was sutured to host bed using 12-16 interrupted sutures using 10-0 nylon.

\subsection{Post Operative Follow up}

All patients received same postoperative medicines (topical fluoroquinolones - four times a day for 2 weeks and steroids topically six times a day for 3 months with slow tapering dose). Graft edema cleared in all patients by $2-3$ weeks. By 1 year, all the sutures were removed, beginning around 6-7 months and were followed up for a minimum 1 year period-on day 1 , first postoperative week, 3 weeks later, 6 weeks, 3 months, 6 months, and then at 1 year later (Figures 1 and 2). No complications were noted on the follow-up visits. On review, visual acuity, postoperative refraction, astigmatism, and Endothelial Cell (EC) count were noted. Statistical analysis was done using SPSS software version 19 . 
and $2.66 \pm 0.7$ and ' $\mathrm{p}$ ' value was significant $(\mathrm{p}=0.00042)$. (Table 2)

Table 2. Preoperative and postoperative comparison of UCVA and astigmatism at 1 year follow up.

\begin{tabular}{llll}
\hline $\mathbf{n}=\mathbf{1 4}$ & PREOPERATIVE & POSTOPERATIVE & 'p' value \\
\hline UCVA (LogMAR) & $1.35 \pm 0.25$ & $0.68 \pm 0.19$ & 0.00001 \\
ASTIGMATISM (D) & $4.82 \pm 1.76$ & $2.66 \pm 0.7$ & 0.00042 \\
\hline
\end{tabular}

Endothelial count was measurable only in eight eyes preoperative and postoperative. Mean value preoperative and postoperative was $2479.18 \pm 239.42$ and

Table 3. Preoperative and postoperative endothelial count at 1 year follow up.

\begin{tabular}{llll}
\hline $\mathbf{n}=\mathbf{1 1}$ & PREOPERATIVE & POSTOPERATIVE & 'p' value \\
\hline ENDOTHELIAL COUNT $\left(\right.$ cells $\left./ \mathrm{mm}^{2}\right)$ & $2479.18 \pm 239.42$ & $2238.45 \pm 218.49$ & 0.00422 \\
\hline
\end{tabular}

Post operatively two cases which developed postoperative double anterior chamber (AC) which needed surgical intervention, and two cases showed wrinkling of DM due to advanced $\mathrm{KC}$ in these patients. Patients with double AC were taken to operation theatre the next day and $\mathrm{AC}$ wash along with chamber formation and release of double AC was done. Postoperative no other complications were noted and all patients recovered well.

\section{Discussion}

Management of keratoconus post hydrops scarred corneas include deep anterior lamellar keratoplasty (DALK) and penetrating keratoplasty (PK). DALK is preferred over PK because if its advantages over PK. However, DALK has a steep learning curve and especially in a case of post healed hydrops where there is pre-existing DM perforation and chances of intraoperative extension of tear is extremely high. These patients have localised scar with astigmatism and poor visual acuity and Anwar's Big Bubble technique is contraindicated in such cases. Therefore, surgical technique of choice still remains debatable in these cases due to the preexisting DM perforation which makes DALK technically difficult in inexperienced hands and few studies like ours have demonstrated good outcome. Our study in addition also includes patients who had a peripheral DM iatrogenic disruption due to surgical wound created following toric ICL (implantable collamer lens) insertion and removal. This also creates a potential wound which can interfere with a future successful DALK.

Multiple previous studies of DALK have demonstrated successful outcomes in cases of healed hydrops. [5-9] Similar case reports of successful DALK in healed hydrops has also been shown by Das et al and Chew et all.[7] Anwar et al have demonstrated near total DALK in 22 eyes with a good outcome.[10]

We have also demonstrated a specific technique of dissection in these patients which reduces chances of intraoperative tear extension and chamber collapse by avoiding injection of air into stroma. Non DM baring DALK is also a successful method to prevent intraoperative DM tear extension in such cases, however, residual significant stroma could leave a visible opacity and also result in poor BCVA.
Our technique specifically does not aim at non DM baring but a centripetal technique of dissection where the dissection is initially carried out at the periphery and then moving gently towards the perforation site. This helps is successful initial dissection of most of the healthy areas and to prevent chances of initial AC perforation and collapse and thus, ensuring successful DALK in pre existing perforation.

The other observation made during this study and also mentioned in our previous study (Kodavoor SK et al) showed that post healed hydrops have scarred edges at the DM perforation site, which helps prevent intraoperative extension and sudden enlargement if careful dissection is done.[11] Jacob et al have showed a technique of DALK in case of acute hydrops. However, fresh DM tear with surrounding stromal edema, poor anterior chamber visualization, difficult trephination, increased inflammation and technical comfort for all are few drawbacks which can hamper with successful outcomes.[12]

\section{Conclusion}

Pre-existing corneal perforation is a relative contraindication for deep anterior lamellar keratoplasty. However, a careful layer by layer dissection from periphery to centre without injecting air or saline into stroma along with careful handling of the perforation site can result in optimal outcome. A larger series for a longer duration can throw more light in these difficult cases.

\section{References}

[1] Das S, Dua N, Ramamurthy B. Deep lamellar keratoplasty in keratoconus with healed hydrops. Cornea. 2007 Oct; 26 (9): 1156-7.

[2] Reinhart WJ, Musch DC, Jacobs DS, Lee WB, Kaufman SC, Shtein RM. Deep anterior lamellar keratoplasty as an alternative to penetrating keratoplasty a report by the american academy of ophthalmology. Ophthalmology. 2011 Jan; 118 (1): 209-18.

[3] Javadi MA, Feizi S, Yazdani S, Mirbabaee F. Deep anterior lamellar keratoplasty versus penetrating keratoplasty for keratoconus: a clinical trial. Cornea. 2010 Apr; 29 (4): 365-71. 
[4] Romano V, Iovieno A, Parente G, Soldani AM, Fontana L. Long-term clinical outcomes of deep anterior lamellar keratoplasty in patients with keratoconus. Am J Ophthalmol. 2015 Mar; 159 (3): 505-11.

[5] Nanavaty MA, Daya SM. Outcomes of deep anterior lamellar keratoplasty in keratoconic eyes with previous hydrops. Br J Ophthalmol. 2012 Oct; 96 (10): 1304-9.

[6] Ramamurthi S, Ramaesh K. Surgical management of healed hydrops: a novel modification of deep anterior lamellar keratoplasty. Cornea. 2011 Feb; 30 (2): 180-3.

[7] Chew ACY, Mehta JS, Tan DTH. Deep lamellar keratoplasty after resolution of hydrops in keratoconus. Cornea. 2011 Apr; 30 (4): 454-9.
[8] Anwar HM, Anwar M. Predescemetic dissection for healed hydrops--judicious use of air and fluid. Cornea. 2011 Dec; 30 (12): 1502-9.

[9] Kodavoor SK, Deb B, Ramamurthy D. Outcome of deep anterior lamellar keratoplasty patients with intraoperative Descemet's membrane perforation: A retrospective crosssectional study. Indian J Ophthalmol. 2018 Nov; 66 (11): 1574-9.

[10] Jacob S, Narasimhan S, Agarwal A, Sambath J, Umamaheshwari G, Saijimol AI. Primary Modified Predescemetic Deep Anterior Lamellar Keratoplasty in Acute Corneal Hydrops. Cornea. 2018 Oct; 37 (10): 1328-33. 